\title{
WRITING THE PAST, WRITING THE FUTURE OF INDONESIA
}

\author{
Joshua Barker and \\ Eric Tagliacozzo
}

We have now edited the journal for seven years, since the Autumn of 2008. In that time, a mere seventh of the time that the journal has actually been in existence-since $1965 / 66$, or fifty years as of Fall 2015-it has become apparent to us how much we stand on the shoulders of giants. It is arguable that, in the last half-century, no other periodical on the country has had as much influence on Indonesian studies globally as this one. If this is true, and we suspect most academics across a wide range of humanities and social science disciplines would likely say it is, then it is, in fact, because of these giants. A number of these scholars have penned short pieces for this special volume to introduce the history of the journal and describe its evolution over time. Their words are instructive. They show how haphazard the building of this institution was from the very beginning: chance, favorable patronage, and good timing were all part of the initial admixture that made it grow. Indonesia almost had a very short life, as its attempts to stand on its own in its earliest years were not at all assured, given the kinds of things it was publishing, and what was happening in the country that time. There were some serious vested interests set against it. Suharto himself wanted it torn down, or at least discredited. But the "elders" (as we have taken to calling them) stood their ground and kept watering the nascent journal, encouraging its development and its own singular voice. That singular vision still survives today - even in some strange quirks, like the nonconformist size and format of the journal - fifty years after the founding. Indonesia is still read quite reliably by a range of people across many fields, all of whom share a deep and abiding interest in the eponymous country. It

Joshua Barker (University of Toronto) and Eric Tagliacozzo (Cornell University) are Indonesia's contributing editors, 2008-present. 
is now a part of the history of Indonesia. The growth of the journal, and the growth of Indonesia itself, are bound together side by side over the decades.

Although there are a number of short contributions at the start of this issue dealing with the founding of the journal, its evolution, and its longevity as a disseminator of information and knowledge about Indonesia, there are also other articles in this, the one-hundreth issue. There is a nice symmetry in the fact that Aceh is present here, as it was in the first volume, so that the "margins" of Indonesia come to the fore. This was not planned. But happy accidents such as this let us pause and think about the mission of the journal, which wanted to deal with not only the central currents of Indonesian life, but also its "edges," and the people and places that are, perhaps, not always highlighted as being part of a normative narrative of the country. We have strived to some degree to work against master narratives in the pages of this journal, and to let the scholarship take us where it will. In this, we continue a tradition of the founders (or again, the "elders") in that we have not tried to force submissions or topics into bailiwicks acceptable to us. Rather, we have attempted to move with the flow of various aliran (or streams), and let these currents of knowledge, topics, and research agendas push us where they will-and not the other way around. We hope this has been in keeping with some of the best traditions of the journal. We see our job as one that reflects this dialectic-a chance to let the "invisible college" of scholars choose the makeup of each issue of the journal through their own selections of work. We merely facilitate. It is our hope that the editors to whom we eventually hand off the journal will also continue this tradition, and will therefore allow the streams of international knowledge-production that make up our submissions to move where they will.

It is tempting to look back at the journal's first one hundred issues and see the past as prologue. Perhaps there are indications in those many hundreds of printed submissions as to what the future of the journal will look like, at least in terms of content. Maybe yes and maybe no. The emphases of scholarship change over time; what seemed worthwhile or even urgent to one generation may not seem so to the next. Certainly Indonesia was born during a period of great political strife in that country, and many of the initial articles dealt with themes that either directly or indirectly had something to do with the incredible spasms of conflict that were occurring in Indonesia at the time. Yet it is noticeable to us, too, that many of the journal's articles do not, in fact, deal with anything of the sort. There has always been a strong current of research on topics just for those topics' own sakes, and not for any other reason. Ethnomusicology, studies of the Chinese minority, cultural interpretations of various rituals, and the fleshing-out of "place" by anthropologists all have significant representation over the past five decades' worth of pages. Even in this commemorative issue, marking a rather significant anniversary of the journal, we have chosen to fold in normative, "everyday" articles with those short pieces at the front of the issue talking about larger themes. We feel this marriage of the two rafts of work represents nicely our own feelings about the centenary issue. This is something that should be noted and celebrated, because of the achievements of the "elders," but it is also just another issue, another chance to publish good work on Indonesia. In this we also keep to tradition, whereby the past editors knew their own place in the scheme of things was (ultimately) minor. The attention has always been first and foremost on Indonesia itself. We hope and think this will always remain so.

As we look ahead, we would like to highlight some of the qualities of the journal that we prize most highly. The first of these could be described as a kind of serious amateurism. This is evident in the design of the journal: its format, fonts, and cover art. But it goes deeper. As Benedict Anderson points out in his piece below, the founders of the journal were inspired by 
the eclectic quality of some of the best Dutch colonial journals, which published articles by amateur historians and social scientists whose knowledge of the Dutch East Indies came from the experiences borne of long-term immersion there. It is also evident that the affirmation of a relatively unstructured and haphazard program of serious scholarly inquiry was consistent with a certain strain of counter-cultural thinking prevalent at Cornell in the 1960s. Yet, if anything, we suggest that this aspect of the journal's identity is even more relevant today. As Jim Siegel points out in his contribution, academia as a whole has undergone a growing professionalization over the last few decades, and in this context the spirit of amateurism and eclecticism is all the more important to preserve. As disciplines hive off from one another and come to take themselves more and more seriously, a journal like Indonesia can provide researchers with a "line of flight" from the constraints and expectations that govern more restrictive journals. That Indonesia can provide this while retaining its high academic standing is a remarkable gift to those of us who study this country. It is also proof that there are other routes to the top than the ones most traveled.

A second quality we prize about the journal is that it has always remained near or at the forefront of scholarly thinking about Indonesia. Since the early years, Indonesia has been regarded as a venue where researchers-often just back from the field or the archive-can quickly share their early stage findings with a readership that is at once receptive, critical, and highly informed. It is a venue where one does not have to spend a great deal of time establishing the scene and the context, since one can assume that one's readers already know who Jokowi is, what a dalang is, when Guided Democracy was, where Tasikmalaya is, how Nahdalatul Ulama differs from Muhammadiyah, and so on. Being able to "cut to the chase" allows ideas to flow more freely and opens up space for including greater empirical depth and richness than might otherwise be possible. At the same time, the efficiency and dedication of those who have kept the machinery of the journal going all these years-Audrey Kahin, Deborah Homsher, Sarah Grossman, Fred Conner, and others-has meant that the writing is well edited, the IndonesianEnglish translations are true, and manuscripts are turned around quickly. All these things have made Indonesia an attractive venue for scholars to bring their latest and best research on the archipelago.

Finally, what we prize most about Indonesia is the not-quite-imagined community that has grown up around it. While the academic excellence of the journal owes much to the exacting standards of its founders, ultimately it is the "college of scholars" that read it, peer review for it, write for it, and cite it that give the journal its character. One of the great pleasures of our task as editors over the past years has been reading the penetrating reports on manuscript submissions, and seeing how papers are refined and sharpened en route to publication. Having the opportunity to take part in this process has confirmed our sense of how open-minded, supportive, serious, and committed our community of Indonesianists really is. We are grateful for the many contributions this community has made to the journal during the past fifty years. And we are looking forward to contributing to, and reading, the journal as it evolves and transforms in the years ahead. 
